\title{
Exchanges of methane between lakes and the atmosphere in Hokkaido, Subarctic Climate Region, Japan
}

\author{
Masafumi Sasaki, Noboru Endoh \\ Department of Mechanical Engineering, Kitami Institute of Technology, Kitami, Japan
}

Email address:

sasaki-m@mail.kitami-it.ac.jp (M. Sasaki)

To cite this article:

Masafumi Sasaki, Noboru Endoh. Exchanges of Methane between Lakes and the Atmosphere in Hokkaido, Subarctic Climate Region, Japan. Journal of Water Resources and Ocean Science. Vol. 3, No. 6, 2014, pp. 89-94. doi: 10.11648/j.wros.20140306.14

\begin{abstract}
Dissolved methane concentrations $(D M)$ at twelve major lakes in Hokkaido, the northernmost island in Japan were observed in the open water season during 2006 2009 to estimate diffusive flux from lake surfaces to the atmosphere. An inverse relationship between lake size and $D M$ was obtained in lakes in Hokkaido as was found for the European boreal lakes. All lake images larger than $0.001 \mathrm{~km}^{2}$ were obtained by image processing of map data and area and number distributions were analyzed in order to calculate mass fluxes of diffusive methane. Total area of all $(1,269)$ lakes in Hokkaido is $809 \mathrm{~km}^{2}$. Regional diffusive flux of methane from lakes to the atmosphere in Hokkaido was estimated to be $0.581 \mathrm{Gg} \mathrm{CH}_{4} \mathrm{yr}^{-1}$. Average diffusive flux density (per lake area) was about $0.718 \mathrm{~g} \mathrm{CH}_{4} \mathrm{~m}^{-2} \mathrm{yr}^{-1}$. This is a similar value to that in European boreal lakes on no-permafrost inland areas. Extremely high flux was found in Lake Abashiri-ko, one of highly eutrophic, meromictic lakes.
\end{abstract}

Keywords: Methane Flux, Lakes, Eutrophication, Global Warming

\section{Introduction}

Methane is well known as one of the green house gases (GHG). Lakes are significant source of methane to the atmosphere. In the previous work [1] [2], it was reported that the anomalous dissolved methane concentrations $(D M)$ were frequently found even in Antarctica. In a subarctic climate zone, Hokkaido, the northernmost island in Japan, because of higher ambient and water temperatures and thicker organic sediments on the lake floors than those in Antarctica, it is expected that more active methanogenesis must be observed. If $D M$ of a lake at the surface is supersaturated to the equilibrium for atmosphere, the lake acts as a methane source in the same manner of oceans [3].

In this study, field observations of $D M$ were carried out mainly in twelve major lakes in Hokkaido in the open water season during 2006-2009. Diffusive mass fluxes of methane from all lakes in Hokkaido to the atmosphere are estimated from the results of the $D M$ measurement and analysis of lake area and number distributions.

\section{Methods}

\subsection{Site Descriptions}

The locations of twelve observed lakes (circles) containing big-3 freshwater lakes in Hokkaido are illustrated in figure 1. The big-3 (70 80 $\left.\mathrm{km}^{2}\right)$ freshwater lakes are Lake Kussyaro-ko, L. Shikotsu-ko and L. Toya-ko. The big-3 and L. Akan-ko are caldera lakes which have hot-sprig wells. Sampling stations are located on the shore of the lakes and off shore approached by a powerboat.

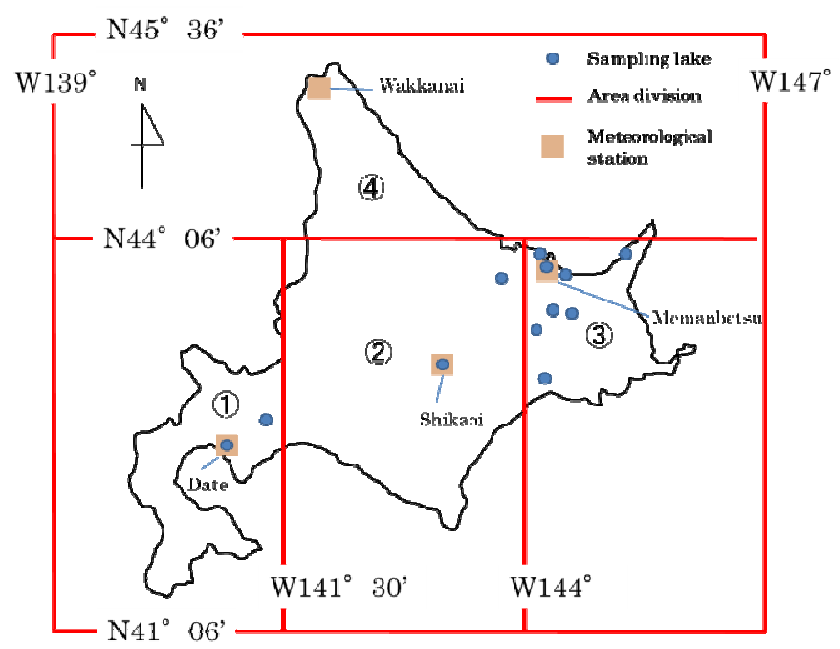

Fig. 1. Observed Lakes in Hokkaido, Japan are shown by circles. Representative meteorological stations 1 4 are shown in solid square. 


\subsection{Sampling Procedures}

Surface water was sampled with a stainless steel pail and Van Dorn water sampler was used for sampling along water column. Temperatures and salinities of the water column were measured by a CTD. The waters were sealed in $500 \mathrm{ml}$ glass vials after overflow procedure. Air was sampled in pre-vacuumed Tedler bags at the height of 1.5 - 2 meters from the ground.

\subsection{Measurement of Dissolved Methane Concentrations (DM)}

A headspace technique was applied to measure $D M$ in water. A part of sample water in three glass vial $(27 \mathrm{ml}$ each) was replaced by pure nitrogen and $10 \mathrm{ml}$ of sample water was remained in the vial. After each vial sample was heated and kept $60{ }^{\circ} \mathrm{C}$ for 20 minutes, headspace gas of $1.625 \mathrm{ml}$ was injected to a gas chromatograph installed FID (GC-FID: Shimadzu GC-8A ).

The measurements of DM were usually finished within 12 hours after sampling. When the samples had to be preserved for a few days or more, however, $\mathrm{HgCl}_{2}$ was added as a preservative to the samples.

\subsection{Measurements of Gas Concentrations in the Air}

The sample air from a Tedler bag was directly injected to a 2 $\mathrm{ml}$ sample loop in the gas sampler which was installed in the same GC-FID mentioned above at the measurements of the methane concentrations in the air. Carbon dioxide concentrations were also measured through a methanizer located before FID. $\mathrm{CO}_{2}$ escapes preferentially out of Tedler bag (3\% and $15 \%$ of maximum reduction after one and three months respectively). The measurements of $\mathrm{CH}_{4}$ and $\mathrm{CO}_{2}$ concentrations were usually finished within 24 hours after sampling.

\subsection{Estimation of Diffusion Flux of Methane from Lakes to the Atmosphere}

A two-film model in air-water gas transfer was first proposed by Liss and Slater [4]. A great number of studies on air-sea exchange have been introduced and summarized by Nightingale and Liss [5]. Mass flux $m\left(\mathrm{~g} \mathrm{CH}_{4} \mathrm{~s}^{-1}\right)$ is expressed as Eq. (1).

$$
m=\mathrm{M}_{\mathrm{CH} 4} k_{\mathrm{CH} 4}\left(D M-D M_{0}\right) A
$$

where, $\mathrm{M}$ is molecular weight, $k$ is transfer coefficient, $D M$ is dissolved methane concentration $\left(D M_{0}\right.$ is equilibrium $D M$ of atmosphere) and $A$ is area of water surface.

The transfer coefficient of $\mathrm{CO}_{2}$ in freshwater in the Schmidt number $S c$ of 600 at $20{ }^{\circ} \mathrm{C}, k_{600}$ was calculated using the empirical formulation Eq. (2) for air-lake exchange proposed by Cole and Caraco [6] .

$$
k_{600}=2.07+0.215 U_{10}^{1.7} \cdot\left(\mathrm{cm} \mathrm{hr}^{-1}\right)
$$

The transfer coefficient of methane $k_{\mathrm{CH} 4}$ can be obtained by the Schmidt number for methane, $S c_{\mathrm{CH} 4}$. as Eq. (3)

$$
\begin{gathered}
k_{\mathrm{CH} 4}=k_{600}\left(S c_{\mathrm{CH} 4} / 600\right)^{-n} . \\
n=0.5\left(U_{10} \geqq 3.6 \mathrm{~m} / \mathrm{s}\right) \\
n=2 / 3\left(U_{10}<3.6 \mathrm{~m} / \mathrm{s}\right) \text { by Deacon [7] } \\
S c_{\mathrm{CH} 4}=v_{\text {freshwater }} / D_{\mathrm{DM}} .
\end{gathered}
$$

Hourly mean wind speeds observed at four representative meteorological observatories were applied as $U_{10}$ (equivalent wind speed at $10 \mathrm{~m}$ in height) to Eq. (2) during the open water season. These locations are shown in Fig. 1 (squares).

\section{Results}

\subsection{DM Measurements}

The results of measurements of $D M$ in surface water are shown in Table 1. There are three big freshwater lakes (70 80 $\mathrm{km}^{2}$ ), Lake Kussyaro-ko, L. Shikotsu-ko and L. Toya-ko in Hokkaido.

Table 1. The results of measurements of DM in surface water in 2006 2009.

\begin{tabular}{lllll}
\hline Lake name & Latitude N & Longitude E & $\begin{array}{l}\text { Area } \\
\mathbf{k m}^{\mathbf{2}}\end{array}$ & $\begin{array}{l}\text { DM nmol } \\
\mathbf{L}^{-\mathbf{1}}\end{array}$ \\
\hline Kussharo & $43^{\circ} 33.533^{\prime}$ & $144^{\circ} 20.350^{\prime}$ & 79.4 & 90 \\
Shikotsu & $42^{\circ} 46.300^{\prime}$ & $141^{\circ} 24.400^{\prime}$ & 78.4 & 34 \\
Toya & $42^{\circ} 34.993^{\prime}$ & $140^{\circ} 51.999^{\prime}$ & 70.7 & 27 \\
Notoro & $44^{\circ} 02.267^{\prime}$ & $144^{\circ} 10.388^{\prime}$ & 58.4 & 73 \\
Abashiri & $43^{\circ} 58.000^{\prime}$ & $144^{\circ} 10.000^{\prime}$ & 32.3 & 587 \\
Mashu & $43^{\circ} 34.694^{\prime}$ & $144^{\circ} 31.799^{\prime}$ & 19.2 & 41 \\
Akan & $43^{\circ} 27.000^{\prime}$ & $144^{\circ} 06.000^{\prime}$ & 13.0 & 114 \\
Shikaribetsu & $43^{\circ} 16.348^{\prime}$ & $143^{\circ} 07.133^{\prime}$ & 3.43 & 285 \\
Mokoto & $43^{\circ} 57.467^{\prime}$ & $144^{\circ} 19.933^{\prime}$ & 1.12 & 449 \\
Rausu & $44^{\circ} 01.826^{\prime}$ & $145^{\circ} 05.186^{\prime}$ & 0.43 & 501 \\
Harutori & $43^{\circ} 58.712^{\prime}$ & $144^{\circ} 24.361^{\prime}$ & 0.37 & 711 \\
Tomisato & $43^{\circ} 51.317^{\prime}$ & $143^{\circ} 45.200^{\prime}$ & 0.21 & 707 \\
\hline
\end{tabular}

\subsubsection{Lake Kussyaro-ko}

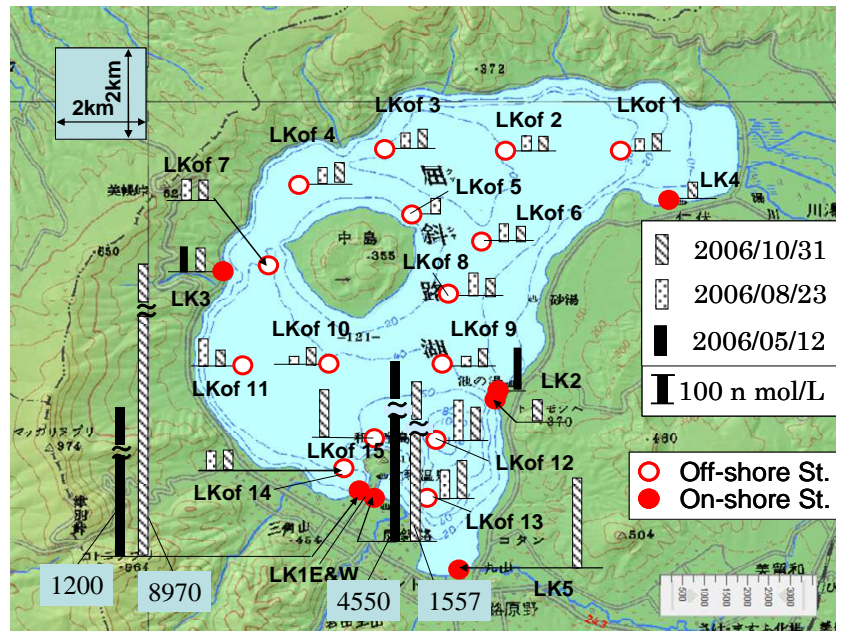

Fig. 2. Surface DM distributions and seasonal changes in Lake Kussyaro-ko, 2006

$D M$ distributions at the surface and seasonal changes in Lake Kussyaro-ko in 2006 are shown in figure. 2. The surface $D M$ s in northern area were lower than those in southern area, 
though the surface water is always super-saturated at every off / on shore station. Seasonal change of $D M$ was not so clear in spite of change in water temperature through May to October.

Since L. Kussyaro-ko is an oligotrophic lake, lower methanogenesis activities at almost all stations are expected. However, there found extremely high $D M$ (more than one $\mu \mathrm{mol} \mathrm{L}{ }^{-1}$ ) along the shore of Wakoto Peninsula (St. LK1E and LK1W). Higher temperature than those at other stations suggested the existence of large amount of hot springs on the lake floor. One of the reasons of the $D M$ anomaly may be higher activity of the methanogenesis because of such higher water temperature. Remarkable anomaly of methane concentrations in the air were seldom observed even around Wakoto Peninsula.

\subsubsection{Lake Shikotsu-ko and Toya-ko}

Both L. Shikotsu-ko and L.Toya-ko are typical oligotrophic lakes. $D M$ distributions at the surface of L.Shikotu-ko on September 11 and that of L. Toya-ko on September 12 in 2007 are shown in figure 3 and figure 4, respectively. Both maximum $D M$ are less than $50 \mathrm{nmol} \mathrm{L^{-1 }}$ and $D M$ are less than $30 \mathrm{nmol} \mathrm{L}{ }^{-1}$ at almost all stations. It is considered that these $D M$ distributions are typically shown in the oligotrophic lakes in Hokkaido, subarctic climate region.

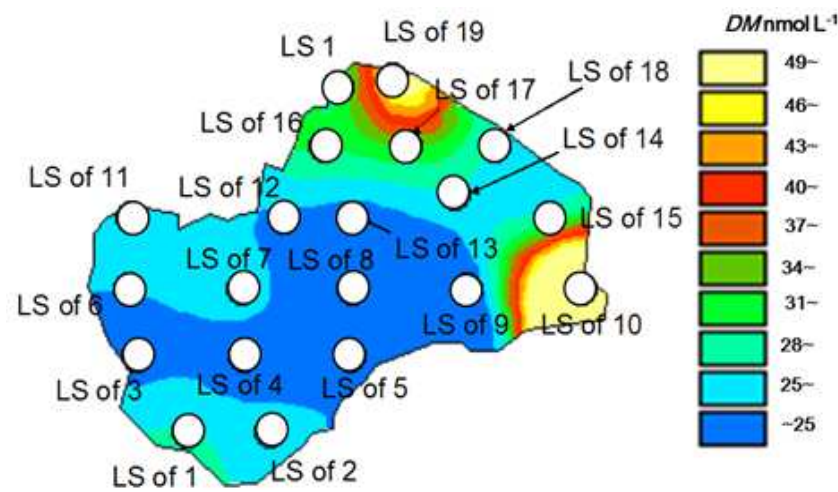

Fig. 3. Surface DM distributions in Lake Shikotsu-ko, on September 11, 2007

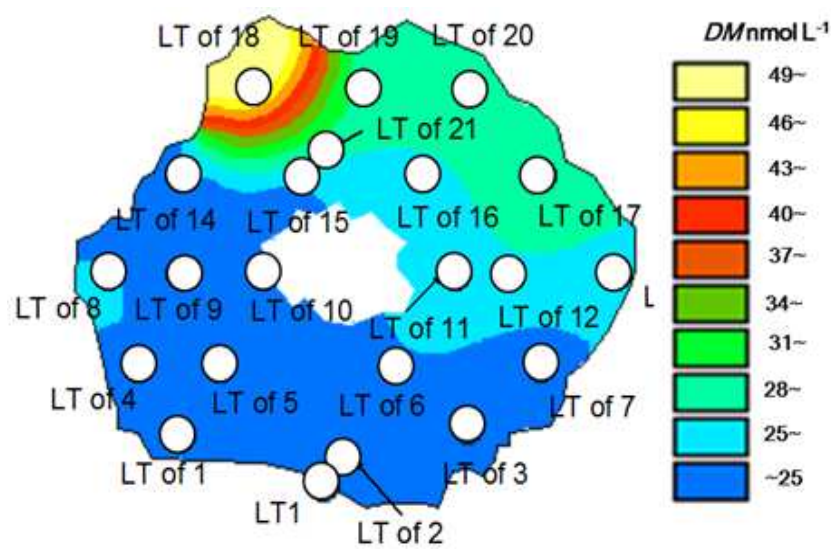

Fig. 4. Surface DM distributions in Lake Toya-ko, on September 12, 2007.

\subsubsection{Lake Akan-ko}

$D M$ distributions at the surface and seasonal changes in 2006 in Lake Akan-ko, one of eutrophic lakes is shown in figure 5. Since seasonal changes in the surface $D M$ can be clearly observed, it seems that the $D M$ strongly depends on water temperature.

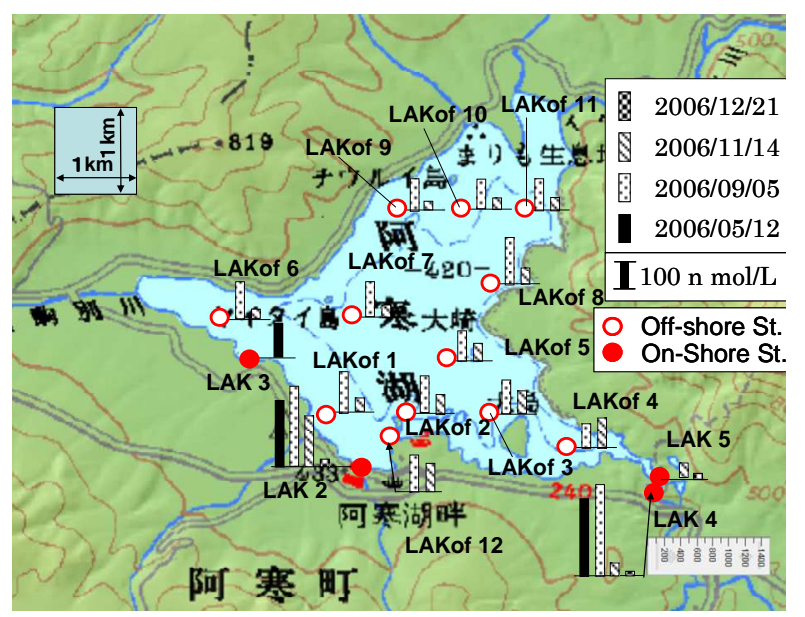

Fig. 5. Surface DM distributions and seasonal changes in Lake Akan-ko, 2006

\subsubsection{Lake Abashiri-ko}

Lake Abashiri-ko is highly eutrophic, meromictic lake. There is a clear saline layer at 5 7 meters deep. It has been eutrophicated by agriculture and pasturage along Abashiri inflow river. $D M$ distributions at the surface in Lake Abashiri-ko are shown in figure 6. Super-saturated $D M$ of 200 times or more than the equilibrium were found at all stations in summer. In early ice-covered season, $D M$ under ice floe generally increased extremely $\left(2 \sim 20 \mu \mathrm{mol} \mathrm{L} \mathrm{L}^{-1}\right)$ on-shore stations. Further study should be carried out to understand the relationship between these anomalous $D M$ and the eutrophication or stratification.

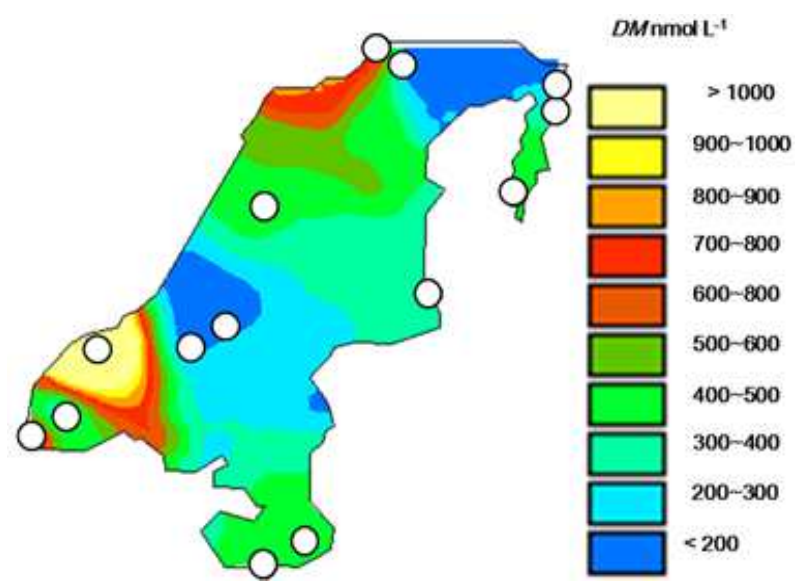

Fig. 6. Surface DM distributions in Lake Abashiri-ko on August 9, 2007

\subsection{Relationship between DM and Lake Size}

In order to determine average $D M\left(=D M_{\mathrm{av}}\right)$ in Table 1 , a lake area was divided into pieces where each station located at near center as shown in figure 7 (Lake Kussyaro-ko as an example). The 'on shore' area was defined as the area of $0 \sim 10$ $\mathrm{m}$ deep (painted out in figure 7) where the sun effectively lightened lake floor. Areal weighted mean DM can be defined as Eq. (5). 


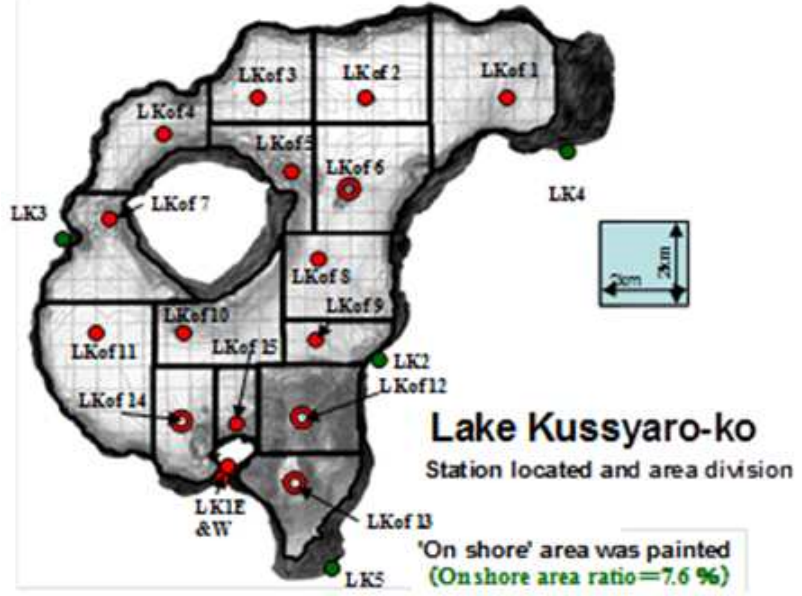

Fig. 7. Area divisions of Lake Kussyaro-ko (Circles show observation stations.)

$$
D M_{\mathrm{av}}=\sum_{\mathrm{K}=1}^{\mathrm{Nst}}\left(D M_{\mathrm{K}} A_{\mathrm{K}} / A\right)
$$

$\mathrm{K}$ : station number $1 \sim \mathrm{N}_{\text {station }}$

Relationships between surface $D M$ and lake area $A$ are shown in Fig. 8. The dotted line in the figure shows Eq. (6) proposed by Bastviken et al [8]. As shown in Fig. 8, Eq. (6) does not express the $D M-A$ relationship in Hokkaido, which has a steeper negative inclination as Eq. (7). One of the reasons of lower $D M$ than those of Eq. (6) in beggar lake area zone is very low $D M$ because of the big oligotrophic lakes as mentioned above. Another one of the reasons of higher DM than those of Eq. (7) in smaller lake area zone may be caused by higher water temperatures in Hokkaido than those in boreal lakes in Europe.

$$
\begin{aligned}
& D M=261.8 A^{-0.227} . \\
& D M=381.6 A^{-0.498}
\end{aligned}
$$

$\left(D M \mathrm{nmol} \mathrm{L}{ }^{-1}, A \mathrm{~km}^{2}\right)$

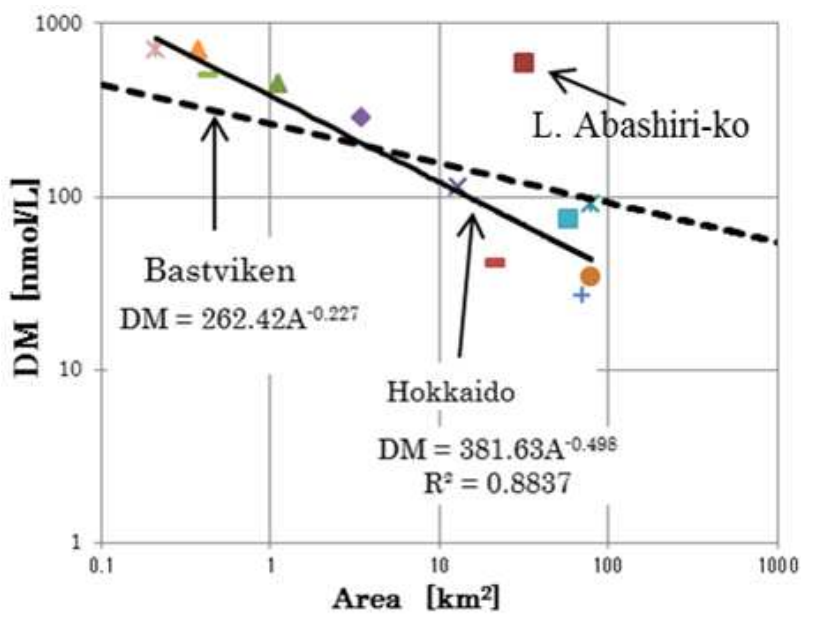

Fig. 8. Relationships between surface DM [nmol $\left.L^{-1}\right]$ and lake area $A\left[\mathrm{~km}^{2}\right]$

$D M$ in L. Abashiri-ko becomes far from this $D M-A$ trend (Eq. (7)) in Hokkaido as shown in Fig. 8. For example, DM in
L. Mokoto-ko, which is also highly eutrophic, meromictic lake like L.Abashiri-ko, corresponds to the relationship Eq. (7). A unique production and migration processes of methane might be expected in this lake. Further observations of DM should be concentrated to L. Abashiri-ko in the future.

\section{Estimations and Discussions of Methane Flux from Lakes to the Atmosphere in Hokkaido}

\subsection{Lake Size and Number Analysis (Individual Lake Area and Regional Histogram of Lake Area)}

Map data (http://maps.google.co.jp/) were referred for lake area analysis. The map images were gradated into two images (black \& white) using 'Adobe Photoshop'. Lakes were expressed as black images. The ratio of black pixels to total pixels was obtained from the histogram of each image (also made by Adobe Photoshop). The product of the black pixel ratio and the analyzing area shows the lake area. Images of rivers and seas were removed by hand before analysis.

All lake images larger than $0.001 \mathrm{~km}^{2}$ were analyzed and area and number (A-N) distributions were obtained in order to calculate mass fluxes of diffusive methane using a commercial particle image analyzer 'A-zokun' made by Asahi Kasei Engineering

Co. (http://www.asahi-kasei.co.jp/aec/business/sensing/product/a zokun.html). Only scale conversion is required to apply this micron scale particles analyzer to kiro-meter scale lakes. The result of $A-N$ analysis is shown in Table 2. Total area of all $(1,269)$ lakes in Hokkaido is $809 \mathrm{~km}^{2}$. Average lake to land area ratio is $1.03 \%$, which is about $1 / 3$ of global average $(2.8 \%$ estimated by Downing et al. [9]). Class i $(=1 \sim 6)$ in Table 2 shows a lake size range between $0.001 \sim 1000 \mathrm{~km}^{2}$. Representative value of $D M$ for every class i was calculated using Eq. (7) for every average lake area.

\begin{tabular}{|c|c|c|c|c|c|c|}
\hline \multirow{2}{*}{$\begin{array}{l}\text { Class } \\
\text { i }\end{array}$} & \multicolumn{2}{|c|}{$\begin{array}{l}\text { Lake area } \\
\text { range }\end{array}$} & \multirow{2}{*}{$\begin{array}{l}\text { Number } \\
\text { of lakes }\end{array}$} & \multirow{2}{*}{$\begin{array}{l}\text { Average } \\
\text { area km² }\end{array}$} & \multirow{2}{*}{$\begin{array}{l}\text { Total } \\
\text { lake } \\
\text { area } \\
\text { km }^{2}\end{array}$} & \multirow{2}{*}{$\begin{array}{l}\text { Ratio of } \\
\text { area to } \\
\text { land }\end{array}$} \\
\hline & $\begin{array}{l}\text { Min } \\
\mathbf{k m}^{2}\end{array}$ & $\begin{array}{l}\operatorname{Max} \\
\mathbf{k m}^{2}\end{array}$ & & & & \\
\hline 1 & 0.001 & 0.01 & 505 & 0.004 & 2.061 & 0.00003 \\
\hline 2 & 0.01 & 0.1 & 544 & 0.033 & 18.121 & 0.00023 \\
\hline 3 & 0.1 & 1 & 163 & 0.328 & 53.393 & 0.00068 \\
\hline 4 & 1 & 10 & 46 & 3.256 & 149.754 & 0.00191 \\
\hline 5 & 10 & 100 & 10 & 44.671 & 446.705 & 0.00570 \\
\hline 6 & 100 & 1000 & 1 & 139.151 & 139.151 & 0.00177 \\
\hline Total & & & 1269 & 0.638 & 809 & 0.01032 \\
\hline
\end{tabular}

Table 2. Area and number (A-N) distributions of lakes from a map analysis in Hokkaido

\subsection{Estimations of Annual Methane Flux from Lakes in Hokkaido}

Hourly mass flux $\Delta m_{\mathrm{ij}}$ at lake size class i was estimated by Eq. (8) (see Eq. 1 4) for a certain $k_{\mathrm{CH} 4}$ calculated with an hourly mean wind speed $U_{10}$ and monthly water temperature $t_{\mathrm{s}}$ at each representative meteorological station $(\mathrm{j}=1 \sim 4)$ as shown in Fig. 1. 
$\Delta m_{\mathrm{ij}}=M_{\mathrm{CH} 4} k_{\mathrm{CH} 4 \mathrm{ij}}\left(D M_{\mathrm{ij}}-D M_{0 \mathrm{j}}\right) A_{\mathrm{ij}} \times 3600 . \quad\left(\mathrm{g} \mathrm{CH}_{4} \mathrm{hr}^{-1}\right)(8)$

Annual mass flux $m_{\mathrm{ij}}\left(\mathrm{g} \mathrm{CH}_{4} \mathrm{yr}^{-1}\right)$ can be estimated by summation of hourly mass fluxes $\Delta m_{\mathrm{ij}}$ during the whole open water period. It is assumed that there was no air-lakes exchange during the ice-covered season. Total annual mass flux in Hokkaido is expressed as the total sum of $m_{\mathrm{ij}}$.

$$
m=\sum_{j=1}^{4} \sum_{i=1}^{6} m_{i j} \quad\left(\mathrm{~g} \mathrm{CH}_{4} \mathrm{yr}^{-1}\right)
$$

Seasonal changes in mass flux of methane from lakes to the atmosphere in Hokkaido are shown in figure 9. Higher flux trend in summer is mainly caused by higher water temperature (= higher $\left.k_{\mathrm{CH} 4}\right)$ in this analysis.

Total annual diffusive methane flux in Hokkaido was estimated to be $0.581 \mathrm{Gg} \mathrm{CH}_{4} \mathrm{yr}^{-1}$. Average flux density (per lake area) is $0.718 \mathrm{~g} \mathrm{CH}_{4} \mathrm{~m}^{-2} \mathrm{yr}^{-1}$. This is similar value to those in European boreal lakes on no-permafrost inland areas (0.923 for Swedish lakes by Bastiviken [8] and 0.784 for Finnish lakes by Juutinen [10]). And this average flux density is about five times greater than that from lakes in Syowa Oasis, in East Antarctica [2],

The annual methane flux in L. Abashiri-ko was estimated to be $0.066 \mathrm{Gg} \mathrm{CH}_{4} \mathrm{yr}^{-1}$. The value corresponds to $11 \%$ of total annual flux in whole Hokkaido, while the lake area of Abashiri-ko occupies only 4\%. The methane flux density in L. Abashiri-ko was 2.029. Such extremely high flux density suggests a unique mechanism of methane cycle. Further observations and analysis must be required for Lake Abashiri-ko.

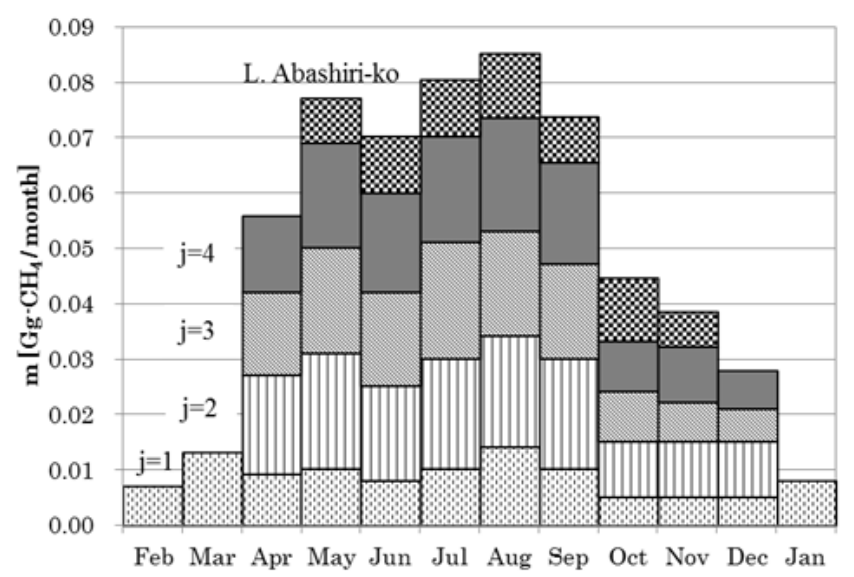

Fig. 9. Seasonal changes in mass flux from lakes in Hokkaido.

\section{Conclusions}

Observations of dissolved methane concentrations $(D M)$ at twelve major lakes in Hokkaido, were carried out in the open water season during $2006 \sim 2009$. Using the results and area histogram analysis of whole lakes larger than $0.001 \mathrm{~km}^{2}$, diffusive methane flux from lake surfaces to the atmosphere were estimated. The study was concluded as follows,

1) An inverse relationship between lake size and DM was obtained in lakes in Hokkaido as was found for the European boreal lakes. The relation slope was steeper than that for the European lakes.

2) Total area of all $(1,269)$ lakes larger than $0.001 \mathrm{~km}^{2}$ in Hokkaido is $809 \mathrm{~km}^{2}$. Regional diffusive flux of methane from lakes to the atmosphere in Hokkaido was estimated to be $0.581 \mathrm{Gg} \mathrm{CH}_{4} \mathrm{yr}^{-1}$. Average diffusive flux density (per lake area) is $0.718 \mathrm{~g} \mathrm{CH}_{4} \mathrm{~m}^{-2} \mathrm{yr}^{-1}$, which is also comparable value for the European boreal lakes.

3) The annual methane flux in L. Abashiri-ko was estimated to be $11 \%$ of total annual flux in whole Hokkaido, while the lake area occupies only $4 \%$. The methane flux density in L. Abashiri-ko was more than five times greater than that expected from the $D M-A$ trend in Hokkaido. Such extremely high flux density suggests a unique mechanism of methane cycle. Further observations and analysis must be required for Lake Abashiri-ko to understand the carbon cycles.

\section{Acknowledgements}

We thank Shota Hirano, Yohei Baba, Toru Wakamatsu, Takuya Jin and Takahiro Kato for valuable assistances in the field works and the analysis. A part of this work was supported by the Japan Society for the Promotion of Science (\#18651011).

\section{References}

[1] Sasaki, M., S. Imura, S. Kudoh, T. Yamanouchi, S. Morimoto and G. Hashida (2009), Methane efflux from bubbles suspended in ice-covered lakes in Syowa Oasis, East Antarctica., J. Geophys. Res., 114, D18114, doi: 10.1029/2009JD011849.

[2] Sasaki, M., N. Endoh, S. Imura, S. Kudoh, T. Yamanouchi, S. Morimoto and G. Hashida (2010), Air-lake exchange of methane during the open water season in Syowa Oasis, East Antarctica., J. Geophys. Res., 115, D16313, doi: 10.1029/2010JD013822.

[3] Liss P.S. and L. Merlivat (1986), Air-sea gas exchange rates: Introduction and synthesis, in The Role of Air-Sea Gas Exchange in Geochemical Cycling, edited by P. Buat-Menard, pp.113-127, D. Reidel, Norwell, Mass.

[4] Liss P.S. and Slater P. (1974), Flux of gases across the air-sea interface, Nature 247, pp.181-184.

[5] Nightingale P.D. and Liss P.S. (2003), Gases in seawater, in The Oceans and Marine Geochemistry, ed H. Elderfield, Vol 6 of A Treatise on Geochemistry (eds Holland and Turekian) Ch 3, 49 -82 .

[6] Cole J. J. and N. F. Caraco, 1998, Atmospheric exchange of carbon dioxide in a low-wind oligotrophic lake measured by the addition of $\mathrm{SF}_{6}$, Limnology and Oceanography, 43(4), 647-656

[7] Deacon, E.L. (1977), Gas transfer to and across an air-water interface, Tellus, 29, 363-374. 
[8] Bastviken, D., J. Cole, M. Pace and L. Tranvik (2004), Methane emissions from lakes: Dependence of lake characteristics, two regional assessments, and a global estimate, Global Biogeochemical Cycles, vol. 18, GB4009, doi: 10.1029/2004GB002238.

[9] Downing, J. A., Y. T. Prairie, J. J. Cole, C. M. Duarte, L. J Tranvik, R. G. Striegl, W. H. McDowell, P. Kortelainen, N. F. Caraco, J. M. Melack and J. J. Middelburg (2006), The global abundance and size distribution of lakes, ponds, and impoundments, Limnology and Oceanography, 51(5), 2388-2397

[10] Juutinen, S., M. Rantakari, P. Kortelainen, J. T. Huttunenn, T. Larmala, J. Alm, J. Silvola and P. J. Martikainen (2009), Methane dynamics in different boreal lake types, Biogeosciences, 6, 209-223. 